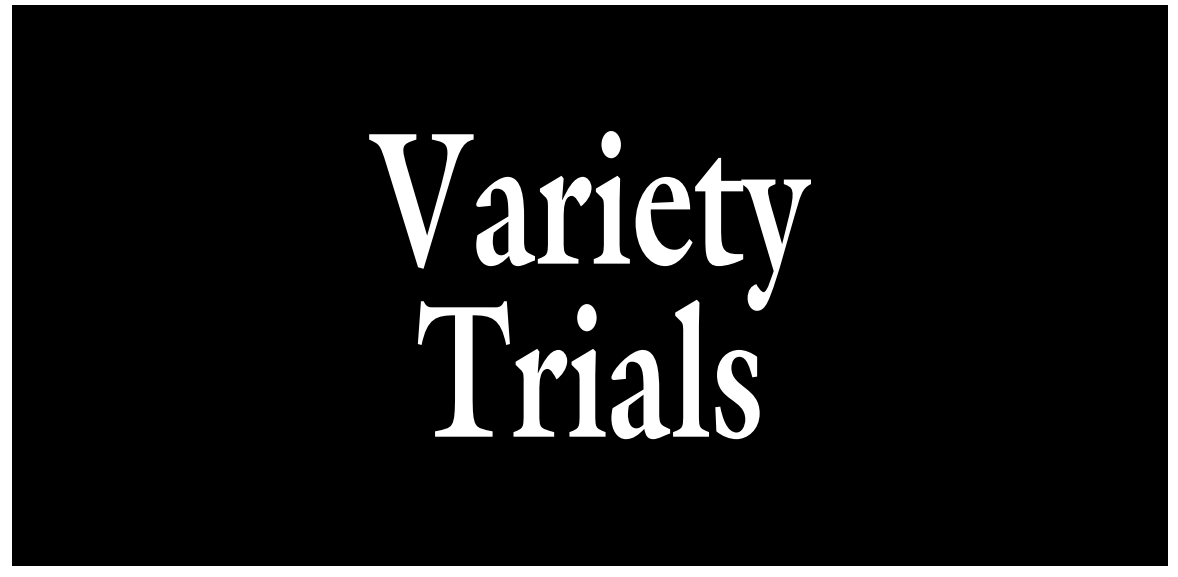

\title{
Performance of High Tunnel Tomato Cultivars in Northern New England
}

\author{
Nicholas D. Warren ${ }^{1,3}$, Rebecca G. Sideman ${ }^{2}$, and \\ Richard G. Smith ${ }^{1}$
}

\begin{abstract}
AdDitional INDEx words. Solanum lycopersicum, hoop house, organic management, radar plots

SuMmARY. Tomato (Solanum lycopersicum) growers select cultivars based on a range of performance criteria. Currently, however, information regarding tomato cultivar performance in high tunnels is lacking. We conducted a tomato cultivar trial in an $1800-\mathrm{ft}^{2}$ plastic-covered high tunnel in Durham, NH, with 15 indeterminate cultivars using organic fertilizers and pesticides. Tomatoes were grown in-ground in a randomized complete block design $(n=4)$ using raised beds with plastic mulch and drip irrigation. Marketable and unmarketable yield, several yield components, and susceptibility to two common diseases, leaf mold (Fulvia fulva) and powdery mildew (Oidium lycopersici or Leveillula taurica), were evaluated over a 3-year period. Differences between cultivars existed in all areas of interest, and year-to-year variation in performance was noteworthy in this experiment. 'Geronimo' consistently had among the highest yields, 'Arbason' and 'Massada' produced many individual fruit, and several cultivars including Rebelski, Massada, and Geronimo showed no signs of disease. Some cultivars such as Conestoga appeared susceptible to several different physiological disorders while others were relatively robust against this type of marketable yield reduction. Because we assessed multiple yield and quality variables and observed apparent trade-offs in several of these, we used radar plots to summarize and communicate the performance of each cultivar in an intuitive and comparable manner. Based on these data, several tomato cultivars appear particularly well suited for high tunnel production in northern New England.
\end{abstract}

$\mathrm{H}$

igh tunnels improve tomato yields and/or quality over both field production (Martinez-Blanco et al., 2011; O'Connell et al., 2012; Rogers and Wszelaki, 2012) and low tunnels (Waterer, 2003). By enabling earlier planting dates and later harvests, high tunnels can extend the growing season, thereby allowing for enhanced growth and the intensification of tomato production in cool climates (Hunter et al., 2012; Uzun, 2007). High tunnels can also protect crops from rain and wind damage and against some pests and diseases (Blomgren and Frisch, 2007;
Wells and Loy, 1993). Because of its high value, tomato has become the principal crop grown in high tunnels in many states (Carey et al., 2009).
Cultivar selection remains a critical component to successful tomato production, and many important traits contribute to cultivar performance in all growing environments, including high tunnels. Traits such as consumer preferences (taste), marketable yield, and yield components such as percentage of unmarketable fruit and the total number of fruit are clearly relevant to growers. Other traits, including susceptibility to disease and physiological disorders, are also important and should be included in the overall assessment of cultivar performance (Hutton and Handley, 2006).

Fungal diseases present a significant challenge to tomato growers. Two of these, leaf mold and powdery mildew, are more prevalent in greenhouse or tunnel production than in open-field systems (Curtis et al., 1994, Jones et al., 2001, Whipps et al., 1998). Leaf mold tends to occur annually in northeastern U.S. high tunnels, whereas powdery mildew is less common, and does not occur every year. Chemical management of both diseases in high tunnels is challenged by limited fungicide options in greenhouses. However, genetic resistance to both diseases exists in tomato cultivars. Resistance to leaf mold is controlled by single race-specific resistance genes that have been widely deployed in cultivars (e.g., Joosten and de Wit, 1999), but it is not known which of the many pathogen races are found in the northeastern U.S. region. Resistance to powdery mildew has been described in a few cultivars (e.g., Seifi et al., 2014), but the response of tomato cultivars to powdery mildew in our region has not been described.

The total marketable yield of a cultivar is governed by the potential to produce fruit and the percentage of that fruit which is damaged to the

\begin{tabular}{llll}
\hline $\begin{array}{l}\text { Units } \\
\text { To convert U.S. to SI, } \\
\text { multiply by }\end{array}$ & U.S. unit & SI unit & $\begin{array}{l}\text { To convert SI to U.S., } \\
\text { multiply by }\end{array}$ \\
\hline 73.0778 & $\mathrm{fl} \mathrm{oz} / \mathrm{acre}$ & $\mathrm{mL} \cdot \mathrm{ha}^{-1}$ & 0.0137 \\
0.3048 & $\mathrm{ft}$ & $\mathrm{m}$ & 3.2808 \\
0.0929 & $\mathrm{ft}^{2}$ & $\mathrm{~m}^{2}$ & 10.7639 \\
2.54 & inch $(\mathrm{es})$ & $\mathrm{cm}$ & 0.3937 \\
1.1209 & $\mathrm{lb} / \mathrm{acre}$ & $\mathrm{kg} \cdot \mathrm{ha}^{-1}$ & 0.8922 \\
28.3495 & $\mathrm{oz}$ & $\mathrm{g}$ & 0.0353 \\
70.0532 & $\mathrm{oz} / \mathrm{acre}$ & $\mathrm{g} \cdot h \mathrm{ha}^{-1}$ & 0.0143 \\
3.9063 & tablespoon $(\mathrm{s}) / \mathrm{gal}$ & $\mathrm{mL} \cdot \mathrm{L}^{-1}$ & 0.2560 \\
$\left({ }^{\circ} \mathrm{F}-32\right) \div 1.8$ & ${ }^{\circ} \mathrm{F}$ & ${ }^{\circ} \mathrm{C}$ & $\left({ }^{\circ} \mathrm{C} \times 1.8\right)+32$
\end{tabular}

Hortlechnology · February 2015 25(1) 
extent that it is no longer marketable. The reason fruit becomes unmarketable is a function of abiotic and biotic factors driven by genetic susceptibility, management, and environmental conditions, or often combinations thereof. Some of the many physiological disorders affecting tomato include blossom-end rot, yellow shoulder, uneven ripening (parts of fruit remaining yellow), and various forms of fruit cracking (Jones et al., 2014). While environmental factors usually determine whether particular disorders will be seen, cultivars differ in their susceptibility to common disorders, and an improved understanding of these differences would help growers minimize the risk of crop loss by selecting less susceptible cultivars.

To our knowledge, there are no data in the peer-reviewed literature from tomato cultivar trials conducted in high tunnels that are applicable to the northeastern United States. There are, however, several informative extension publications available for various regions in the United States (e.g., Bogash, 2011; Monroe et al., 2010). The purpose of this experiment was to evaluate, describe, and communicate the important differences in yield and susceptibility to common diseases and disorders among 15 tomato cultivars in a high tunnel production system under conditions typical for the northeastern United States (i.e., raised beds, plasticulture, and irrigation) (Lamont et al., 2003).

\section{Materials and methods}

SITE DESCRIPTION AND EXPERIMENTAL DESIGN. The experiment was conducted for three growing

Partial funding was provided by the New Hampshire Agricultural Experiment Station. This is Scientific Contribution Number 2575. This work is supported by the USDA National Institute of Food and Agriculture, Hatch Project NH00586.

We would like to thank K. Orde, L. Worthen, K. Juntwait, J. Cain, D. Tauriello, and L. Atwood for technical assistance. Additionally we thank J. McLean and E. Ford at UNH Woodman Research Farm and D. Goudreault and J. Ebba at the UNH MacFarlane Greenhouses for their assistance. Thanks also to J.E. Carroll, M. Simmons, and F. Pollnac for their review of a previous version of the manuscript.

${ }^{1}$ Department of Natural Resources and the Environment, University of New Hampshire, 56 College Road, Durham, NH 03824

${ }^{2}$ Department of Biological Sciences, University of New Hampshire, 38 Academic Way, Durham, NH 03824

${ }^{3}$ Corresponding author. E-mail: Nicholas.Warren@ UNH.edu. seasons from 2011 to 2013 in a $30 \times$ $60 \mathrm{ft}$ high tunnel at the University of New Hampshire (UNH) Woodman Horticultural Farm in Durham. The high tunnel was managed in accordance with U.S. Department of Agriculture organic production standards. Each season, the tunnel was prepared by rototilling, fertilizing, and forming beds using a small tractor-mounted bed former with 36-inch black plastic mulch and drip tape irrigation. Weeds between rows were controlled by hand and mulching with salt marsh hay. The study was a randomized complete block design with plots of four plants of each cultivar replicated in four blocks. In late May, tomatoes were transplanted directly into the ground in single rows and spaced 16 inches between plants with rows 55 inches apart.

In Winter 2011, we developed and conducted a survey to solicit input from local growers on cultivars to evaluate, and which variables to measure during the experiment. This information, combined with additional conversations with growers and extension professionals, was used to select 11 indeterminate beefsteak cultivars in 2011. Of all available tomato types grown in high tunnels, indeterminate tomato cultivars were selected to meet growers' interests and ensure between-cultivar observations were comparable. In 2012, three additional cultivars were added, and one was substituted in 2013. All cultivars were hybrids with the exception of Brandywine, an open-pollinated heirloom type. A full list of cultivars and seed suppliers can be found in Table 1 .

Before each growing season, high tunnel soil tests were submitted through UNH Cooperative Extension to obtain fertility recommendations for commercial tomato production. Fertilizers were applied according to standard production guidelines (Howell and Hazzard, 2012). To meet these targets, in 2011 , we applied soybean meal $[7 \mathrm{~N}-0.9 \mathrm{P}-1.7 \mathrm{~K}$ (Blue Seal, Muscatine, IA)] at a rate of 2050 $\mathrm{lb} /$ acre. In 2012, we applied soybean meal at a rate of $915 \mathrm{lb} /$ acre and sulfate of potash magnesia $[0 \mathrm{~N}-0 \mathrm{P}-$ $18.6 \mathrm{~K}$ (Fertrell, Bainbridge, PA)] at a rate of $107 \mathrm{lb} /$ acre before bed formation, and we side-dressed twice with liquid fish-seaweed blend [ $2 \mathrm{~N}-$ 1.3P-0.8K (Neptune's Harvest, Gloucester, MA)], both times at a rate of $5.7 \mathrm{oz} /$ acre. In 2013, manure-based compost $(1.4 \mathrm{~N}-0.4 \mathrm{P}-$ $0.3 \mathrm{~K}$ ) was incorporated at a rate of $120 \mathrm{yard}^{3} /$ acre, along with organic fertilizer [5N-1.3P-3.3K (Pro-Gro; North Country Organics, Bradford, $\mathrm{VT})$ ] at a rate of $2000 \mathrm{lb} / \mathrm{acre}, 1600$

Table 1. Tomato cultivars, seed sources, and observed susceptibility to powdery mildew and leaf mold in a high tunnel tomato cultivar trial conducted over 3 seasons from 2011 to 2013 in Durham, $\mathbf{N H}$.

\begin{tabular}{|c|c|c|c|c|c|c|c|}
\hline \multirow[b]{2}{*}{ Cultivar } & \multicolumn{3}{|c|}{ Yr grown } & \multirow{2}{*}{$\begin{array}{c}\text { Seed } \\
\text { source }^{\mathrm{z}}\end{array}$} & \multicolumn{2}{|c|}{$\begin{array}{l}\text { Leaf mold } \\
(0-4 \text { scale })^{\mathrm{y}}\end{array}$} & \multirow{2}{*}{$\begin{array}{c}\text { Powdery mildew } \\
\text { (0-4 scale })\end{array}$} \\
\hline & 2011 & 2012 & 2013 & & 2012 & 2013 & \\
\hline Arbason & $\mathrm{x}$ & $\mathrm{x}$ & $\mathrm{x}$ & JSS & 3 & 2 & 0 \\
\hline Big Beef & $\mathrm{x}$ & $\mathrm{x}$ & $\mathrm{x}$ & HS & 2 & 3 & 1 \\
\hline Brandywine & $\mathrm{x}$ & $\mathrm{x}$ & $\mathrm{x}$ & HS & 0 & 2 & 2 \\
\hline Cobra & $\mathrm{x}$ & $\mathrm{x}$ & $\mathrm{x}$ & JSS & 1 & 2 & 3 \\
\hline Conestoga & $\mathrm{x}$ & $\mathrm{x}$ & $\mathrm{x}$ & HS & 4 & 4 & 4 \\
\hline Geronimo & $\mathrm{x}$ & $\mathrm{x}$ & $\mathrm{x}$ & JSS & 0 & 0 & 0 \\
\hline Goliath & & $\mathrm{x}$ & $\mathrm{x}$ & HPS & 4 & 3 & 1 \\
\hline Imperial 643 & $\mathrm{x}$ & $\mathrm{x}$ & & $\mathrm{RP}$ & 0 & $\mathrm{NA}^{\mathrm{x}}$ & 0 \\
\hline Jet Star & $\mathrm{x}$ & $\mathrm{x}$ & $\mathrm{x}$ & HS & 2 & 2 & 2 \\
\hline Lola & $\mathrm{x}$ & $\mathrm{x}$ & $\mathrm{x}$ & HM & 1 & 2 & 1 \\
\hline M. Washington ${ }^{\mathrm{w}}$ & & $\mathrm{x}$ & $\mathrm{x}$ & JSS & 3 & 2 & 2 \\
\hline Massada & $\mathrm{x}$ & $\mathrm{x}$ & $\mathrm{x}$ & JSS & 0 & 0 & 0 \\
\hline Panzer & & & $\mathrm{x}$ & HS & NA & 0 & NA \\
\hline Rebelski & & $\mathrm{x}$ & $\mathrm{x}$ & JSS & 0 & 0 & 0 \\
\hline Trust & $\mathrm{x}$ & $\mathrm{x}$ & $\mathrm{x}$ & JSS & 2 & 0 & 2 \\
\hline
\end{tabular}

${ }^{z}$ JSS = Johnny's Selected Seeds (Winslow, ME), HS = Harris Seeds (Rochester, NY), SW = Seedway (Hall, NY), HPS $=$ Horticultural Products and Services (Randolph, WI), RP = Rupp Seeds (Wauseon, OH), HM = High Mowing Organic Seeds (Wolcott, VT).

${ }^{\mathrm{y}} 0$ = no symptoms, $4=$ severe symptoms throughout the entire plant.

${ }^{\mathrm{x}}$ Cultivar was not grown in that season (see Table 1 for details).

w'Martha Washington'. 
$\mathrm{lb} /$ acre sulfate of potash magnesia, and $1650 \mathrm{lb} /$ acre soybean meal. All dry fertilizers were broadcast uniformly across the soil surface and incorporated into the soil before planting.

The tomatoes were germinated at the UNH MacFarlane Greenhouses and transferred to seedling trays $\approx \mathrm{l}$ week after germination. They were moved to the high tunnel to harden off for $2 \mathrm{~d}$ and transplanted into the ground on 20 May 2011, 23 May 2012, and 20 May 2013. Plants were trained to a single leader using a string trellis, and side shoots and lower leaves were pruned weekly or as needed throughout the growing season. The high tunnel was irrigated to the approximate equivalent of 1 inch of rain per week. To maintain consistent soil moisture, the high tunnel was irrigated when the soil $1-3$ inches underneath the plastic mulch became dry to the touch, generally two to three times per week.

Yellow-striped armyworm (Spodoptera ornithogalli) and tomato hornworm (Manduca quinquemaculata) occurred in all 3 years and were controlled by applying Bacillus thuringiensis [Bt (DiPel; Valent BioSciences, Libertyville, IL)] at the rate of $0.5 \mathrm{lb} /$ acre or spinosad [ spinosyn A (Entrust; Dow AgroSciences, INpolis, IN)] at the rate of $1.5 \mathrm{fl} \mathrm{oz} /$ acre as needed. Additionally, potassium bicarbonate (MilStop; BioWorks, Victor, NY) was applied at a rate of 1 tablespoon/gal per $500 \mathrm{ft}^{2}$ in intervals in late 2012 to minimize the spread of powdery mildew.

DATA COLLECTION AND ANALYSIS. Weather data were obtained from the UNH weather station located in Durham, NH. Missing data from 3 Aug. to 25 Aug. 2011 were supplemented with temperatures from Weather Underground Inc. for Durham, $\mathrm{NH}$. Mean daily temperatures from 20 May through 30 Sept. (transplanting through final harvest date of 2013) were used to calculate growing degree days (GDD) with a base temperature of $10{ }^{\circ} \mathrm{C}$ (McMaster and Wilhelm, 1997; O’Connell et al., 2012).

Harvest of mature tomato fruit occurred about weekly from mid-July to late Oct. 2011 and 2012. In 2013, tomatoes were harvested until late September. The final year was shorter to accommodate a transition to winter high tunnel vegetable production.
The tomatoes were left to fully ripen on the vine and were edible at the time of picking. Fruit quality (marketability), weight, number, and the presence of physiological disorders or disease were recorded for each plot at each harvest date. Fruits with minor fruit defects, such as mild cosmetic cracks or scars, were considered "marketable." Fruits showing evidence of disease, damage, or physiological disorders that could affect postharvest storage of the fruit were considered unmarketable.

Several qualitative factors were evaluated during the experiment. Informal taste tests were conducted in each of the growing seasons, but due to the excessive variability observed, the results are omitted from this report. Visual ratings were used to assess cultivar susceptibility to powdery mildew and leaf mold. Each disease was given a leaf infection rating using a scale of 0 (absent) to 4 (severe) during the peak of their respective outbreaks. In both cases, a score of $0=$ no symptoms on any leaves and $4=$ sporulating lesions on nearly the entire leaf surface throughout the plant.

Yield data were converted to total seasonal production of marketable or unmarketable fruit per plant. The total unmarketable weight was used to calculate the percentage of unmarketable fruit. The total number of fruit per plant and average fruit weight were both calculated using marketable yields only. Consistent production between individual plants of the same cultivar (i.e., yield stability) is a desirable trait; as a measure of yield stability, the plot to plot variability of a cultivar's marketable yield was assessed by calculating the $\mathrm{CV}$ for each growing season and this metric is reported in radar plots (see below).

The frequency of common physiological disorders and other causes of tomato damage are reported as the percentage of harvest dates in which each disorder was present on at least one tomato. Disorders that did not appear on at least $15 \%$ of the harvest dates for at least one cultivar were omitted. Disorders that were prevalent in at least 1 year included blossom-end rot, catfacing, radial and concentric cracking, yellow shoulder, splitting, and uneven ripening (Jones et al., 2014). Incidence of each disorder in each year is presented in a simplified $0-4$ scale, where $0=0 \%$, $1=1 \%$ to $24 \%, 2=25 \%$ to $49 \%, 3=$ $50 \%$ to $74 \%$, and $4=75 \%$ to $100 \%$.

Yield and yield component data were checked for normality and analyzed using analysis of variance. The percentage of unmarketable yield was analyzed similarly to the yield data after it was arcsine square root transformed and subsequently tested using the Shapiro-Wilks goodness of fit test for a normal distribution. Cultivar and block were considered fixed effects, and in cases where there was a significant cultivar by year interaction, results are reported separately by year. All analyses were conducted using JMP Pro 11 (SAS Institute, Cary, NC).

Cultivar trial data are typically presented in a univariate manner although multiple variables are assessed in such studies. Radar plots (also known as spider plots) provide a convenient and intuitive way of presenting and evaluating multivariate agricultural data (Smith et al., 2011). Radar plots incorporate three or more axes, with each axis representing a particular variable and sharing a common origin. The original data for each axis may have been collected at various scales and often those data are set to a relativized scale to facilitate comparisons across axes and variables. For each variable in this cultivar trial, the maximum observed value was scaled to the maximum axis value of 50 , and the minimum observed value was scaled to the minimum axis value of 1 , to emphasize differences between cultivars. In this case, the axes represent six variables: the total number of marketable fruit, total marketable yield in weight, average individual fruit weight, the percentage marketable fruit by weight (inverse of percentage of unmarketable fruit), yield stability or the consistency in production between plots (inverse of the $\mathrm{CV}$ ), and the resistance to leaf mold (inverse of susceptibility). The size and symmetry of the resulting polygon indicates the relative magnitude of each variable and the overall performance of the cultivar. Radar figures were generated using Excel 2013 (Microsoft Corp., Redmond, WA).

\section{Results}

The mean seasonal daily temperatures for the periods from 20 May to 30 Sept. 2011, 2012, and 2013 were $19.7,19.5$, and $19.1{ }^{\circ} \mathrm{C}$, respectively. 
The cumulative GDD for the same periods were 1303,1275 , and 1221 , respectively.

The mean marketable yield of the 10 cultivars present in all 3 years of the experiment declined from 8195 $\mathrm{g} /$ plant in 2011 to $3232 \mathrm{~g} /$ plant in 2013 (year, $P<0.001$ ). The relative differences between these same cultivars were inconsistent over the 3 years (cultivar $\times$ year interaction, $P<$ 0.0001 ). For these reasons, as well as the substitutions of some cultivars, yield data were analyzed separately by year.

'Geronimo' consistently produced the highest marketable yields or was not significantly different from the highest yielding cultivar for all 3 years of the study; Arbason, Big Beef,
Imperial 643, and Rebelski all had among the highest marketable yields in at least 2 of the 3 years (Table 2). In contrast, 'Lola', 'Trust', and 'Conestoga' produced among the lowest yields in at least 2 years of the study.

The percentage of unmarketable fruit ranged from $19 \%$ to $47 \%$ in 2011 , $24 \%$ to $44 \%$ in 2012 , and $15 \%$ to $52 \%$

Table 2. Marketable yield and the percentage of unmarketable yield for each tomato cultivar grown in a high tunnel cultivar trial from 2011 to 2013 in Durham, NH.

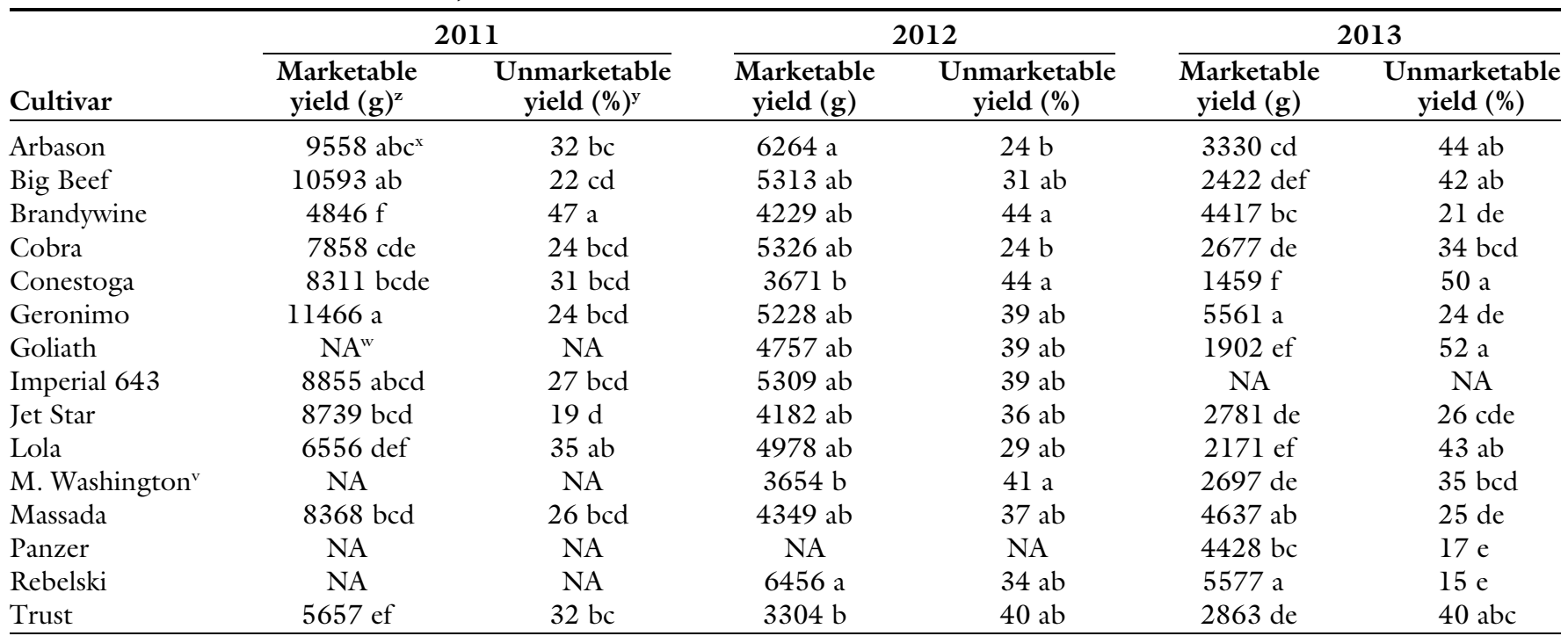

${ }^{\mathrm{z}}$ Mean marketable yield produced throughout the entire season; $1 \mathrm{~g}=0.0353 \mathrm{oz}$.

yy weight.

${ }^{x}$ Within a column, means followed by the same letter are not significantly different at $P \leq 0.05$ using Tukey's honestly significant difference test.

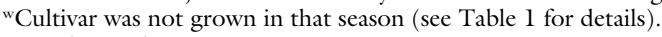

"Martha Washington'.

Table 3. Total number of marketable fruit and average weight of individual fruit, per tomato plant, for cultivars grown in a high tunnel cultivar trail from 2011 to 2013 in Durham, NH.

\begin{tabular}{|c|c|c|c|c|c|c|}
\hline \multirow[b]{2}{*}{ Cultivar } & \multicolumn{2}{|c|}{2011} & \multicolumn{2}{|c|}{2012} & \multicolumn{2}{|c|}{2013} \\
\hline & Fruit (no.) $^{\mathrm{z}}$ & Avg fruit wt $(g)^{y}$ & Fruit (no.) & Avg fruit wt (g) & Fruit (no.) & Avg fruit wt (g) \\
\hline Arbason & $44 \mathrm{ab}^{\mathrm{x}}$ & $220 \mathrm{bc}$ & $29 \mathrm{a}$ & 215 cde & $19 \mathrm{ab}$ & $175 \mathrm{~d}$ \\
\hline Brandywine & $17 \mathrm{e}$ & $293 a$ & $11 \mathrm{f}$ & $380 \mathrm{a}$ & $11 \mathrm{efg}$ & $406 a$ \\
\hline Cobra & $34 \mathrm{bcd}$ & $231 \mathrm{~b}$ & $27 \mathrm{abc}$ & 198 de & 14 bcdef & $187 \mathrm{~d}$ \\
\hline Conestoga & $39 \mathrm{abc}$ & $213 \mathrm{bc}$ & 20 bcde & $185 \mathrm{de}$ & $9 \mathrm{fg}$ & $166 \mathrm{~d}$ \\
\hline Imperial 643 & $30 \mathrm{~cd}$ & $294 \mathrm{a}$ & $18 \mathrm{def}$ & $287 \mathrm{~b}$ & NA & NA \\
\hline Jet Star & $37 \mathrm{abc}$ & $236 \mathrm{~b}$ & 19 cde & 222 cde & 15 bcde & $192 \mathrm{~d}$ \\
\hline Lola & 28 cde & $236 \mathrm{~b}$ & 24 abcd & 208 cde & 13 defg & $174 \mathrm{~d}$ \\
\hline M. Washington ${ }^{\mathrm{v}}$ & NA & NA & 17 def & 208 cde & 14 bcdef & $188 \mathrm{~d}$ \\
\hline Massada & $47 \mathrm{a}$ & $177 \mathrm{c}$ & $27 \mathrm{ab}$ & $158 \mathrm{e}$ & $25 \mathrm{a}$ & $189 \mathrm{~d}$ \\
\hline
\end{tabular}

${ }^{\mathrm{z}}$ Mean number of marketable fruit produced (total per plant) throughout the entire season.

${ }^{\mathrm{y}} 1 \mathrm{~g}=0.0353 \mathrm{oz}$.

${ }^{x}$ Within a column, means followed by the same letter are not significantly different at $P \leq 0.05$ using Tukey's honestly significant difference test.

${ }^{\mathrm{w}}$ Cultivar was not grown in that season (see Table 1 for details).

"Martha Washington'. 
in 2013 (Table 2). 'Brandywine' had one of the highest percentages of unmarketable fruit in the first 2 years but not in 2013, and 'Conestoga' had among the highest in the last 2 years of the study. The cultivars with the lowest percentages of unmarketable fruit varied from season to season, but Cobra produced a relatively low percentage of unmarketable fruit throughout the experiment.

'Massada' and 'Arbason' consistently had the highest numbers of individual marketable fruit; 'Brandywine' and 'Trust' and others had low numbers of fruit in 2011 and 2012, as did 'Goliath' and 'Conestoga' in 2013, and several others (Table 3). Relative to yields, average fruit weight was more stable across the 3 years, following a generally decreasing trend as overall yields declined. 'Brandywine', however, increased in fruit size over 3 years, and 'Geronimo', 'Massada', and 'Trust' remained relatively unchanged.

Leaf mold was not present in 2011, but incidence of this disease was high in both 2012 and 2013 . Powdery mildew was present only in 2012. Qualitative assessments showed that 'Conestoga' and 'Goliath' were the most susceptible to leaf mold, and 'Arbason', 'Big Beef', and 'Martha Washington' were also highly susceptible (Table 1). In contrast, 'Geronimo', 'Massada', and 'Rebelski' appeared resistant both years that leaf mold incidence was high (2012 and 2013). These three cultivars, along with Arbason and Imperial 643, also appeared resistant to powdery mildew in 2012 .

The observed frequencies of physiological disorders are presented in Table 4. Overall incidence of the different physiological disorders varied from year to year. Generally, 'Conestoga' tended to exhibit a high frequency of several disorders (blossom-end rot, catfacing, and radial cracking) across years, while other cultivars were more closely associated with only one or two disorders. 'Martha Washington', 'Rebelski', and 'Jet Star' had a high incidence of blossom-end rot. 'Brandywine' was particularly susceptible to radial and concentric cracking and splitting; 'Arbason', 'Big Beef', and 'Goliath' frequently suffered from radial cracking. 'Imperial 643' was characterized by uneven ripening in the

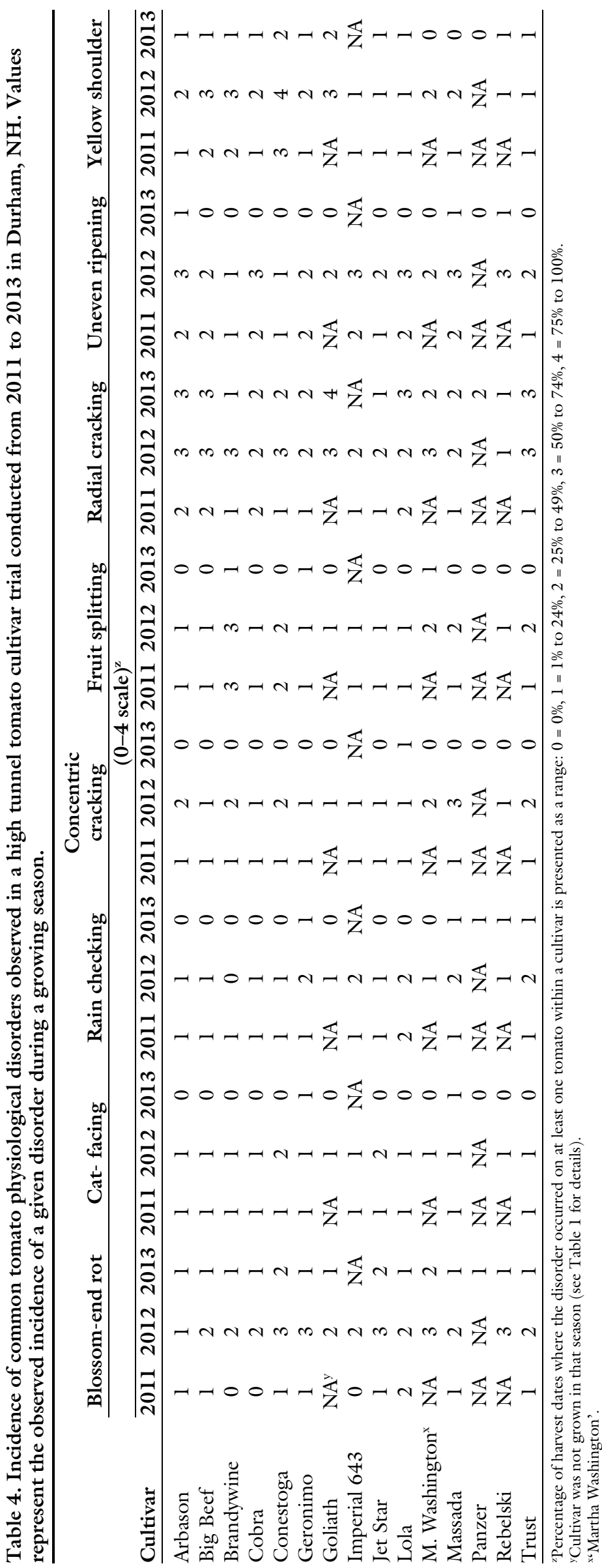




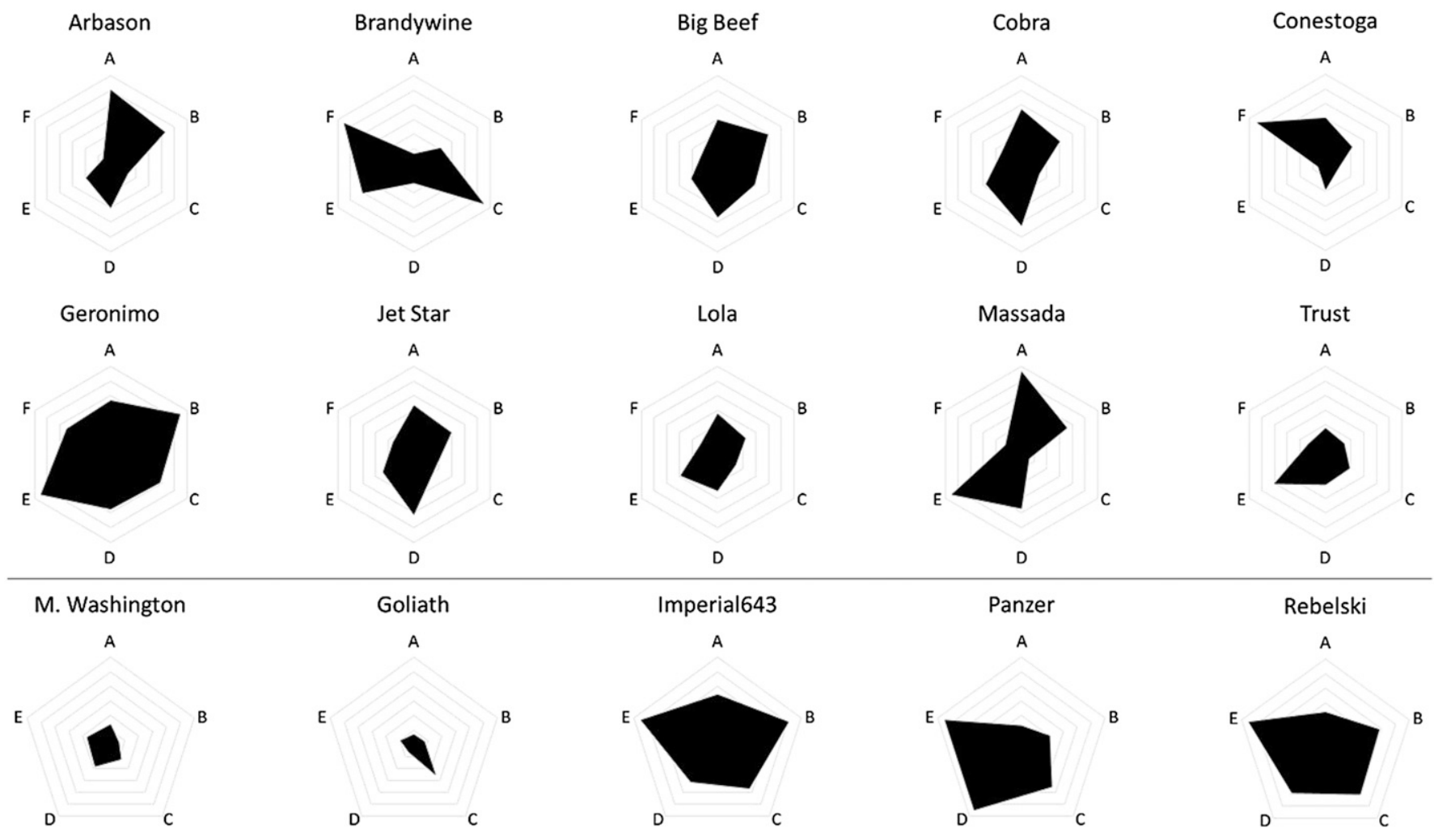

Fig. 1. Radar plots depicting the relative differences for six performance variables among tomato cultivars grown in a high tunnel cultivar trial from 2011 to 2013 in Durham, NH. Each axis represents a single variable. The data for each variable have been scaled so that the minimum and maximum observed values are set to 1 and 50 , respectively. Each axis value represents a mean of three seasons (note exceptions, see Table 1 for details) and the axes represent (A) the total number of marketable fruit, (B) marketable yield, (C) average individual marketable fruit weight, (D) the percentage marketable fruit by weight, (E) the observed severity of leaf mold, and (F) yield stability or the consistency in production between plots (the inverse of the CV). Yield stability (F) was not calculated if a cultivar was grown $<3$ years (bottom row). Innermost rings represent the "least" or "lowest" value relative to other cultivars in the study, and outermost rings the "most" or "highest"; M. Washington = "Martha Washington'.

first 2 years when uneven ripening was prevalent.

Radar plots were used to present the relative magnitude of differences among the cultivars for the whole suite of response variables that were measured (Fig. 1). This approach allows for an efficient comparison of potential trade-offs between cultivars in terms of multiple performance traits. For example, both 'Arbason' and 'Rebelski' had relatively high yields; however, they differed in the size and number of fruit; 'Arbason' with many smaller fruit and 'Rebelski' with larger but fewer numbers of fruit. Some cultivars, such as Martha Washington, Goliath, or Conestoga, stood out as not having any relative "strengths" compared with the others. In contrast, some cultivars, including Cobra, Big Beef, and Arbason, appear generally "balanced" by having relatively desirable values for many of the performance variables that were measured. Both 'Geronimo' and 'Rebelski' had high yields, similar percentages of unmarketable fruit, and good leaf mold resistance.

\section{Discussion}

Given its economic and cultural importance, tomato offers a unique connection between growers and consumers, especially in a direct-market context. Cultivar choice, therefore, remains one of the most important decisions that growers make (Williams and Roberts, 2002). Differences among cultivars in growth habit, disease resistance, and a host of other traits means that growers must make decisions based on their willingness to accept trade-offs in performance traits between cultivars.

The inconsistency in yield across years and within cultivars was unexpected. Overall, we observed a declining trend in production over the
3 years of the study, possibly due to soil nutrient depletion and increases in pathogen pressure in our high tunnel. However, soil tests and subsequent fertility applications throughout the experiment should have compensated for nutrient deficiencies developing over time. While the third harvest season was shorter than the first two, the marketable yield totals for a standardized season length follow the same trend, declining over the 3 years. Anecdotal evidence suggests that this general decline is common in high tunnels new to tomato production, and we also do not rule out the cumulative effects of disease pressure in the tunnel increasingly affecting at least some of the cultivars. There were several notable deviations from the general trend of decreasing yields. The cultivars Geronimo, Massada, Trust, and Rebelski had consistent yields in the final 2 years of the experiment, while Brandywine, which 
despite having low yields relative to other cultivars in 2011 , maintained the most consistent yield of any cultivar over the entire experiment.

We observed stark differences among the cultivars in susceptibility to leaf mold (2012 and 2013) and powdery mildew (2012). When considering both disease resistance and marketable yield results, some cultivars such as Geronimo, Rebelski, and Massada performed very well. Whether the cultivar with the highest yield is the most appropriate choice for growers is a matter of debate. Quality could be measured in many ways, and of particular importance is taste. We conducted multiple informal taste tests each year of the experiment, but unfortunately found a high degree of variability in responses between tests. We observed that the variability exhibited between tasting dates, tasters, and individual tomatoes exceeded detectable differences between the cultivars.

With physiological disorders of tomato, the relationship between cause and effect is often complex. For example, the underlying cause of blossom-end rot is a calcium deficiency (Taylor and Locascio, 2004); however, environmental factors that can interact with calcium dynamics, such as water stress, salinity, temperature, and nutrient source and availability, play an important role in this disorder (Cimen et al., 2010; Paradikovic et al., 2010; Saure, 2001; Taylor and Locascio, 2004). Similarly, while cracking disorders may fundamentally be driven by water dynamics (Peet and Willits, 1995), other factors also contribute to the condition (Emmons and Scott, 1997). Despite the underlying complexity, changes in management can mitigate disorders and improve marketable yields. Documenting the susceptibility of cultivars to particular disorders when grown under uniform conditions can be a useful contribution of cultivar trials so that growers can appropriately accept risk or adopt mitigating management strategies. We found stark differences in the prevalence of certain disorders among the cultivars, and addressing these through high tunnel management or cultivar selection could improve yields.

Researchers who conduct cultivar trials, regardless of the crop species being evaluated, typically collect and report data on several important crop performance traits. These data are often reported in separate tables or figures. The relative importance of each of these performance traits may be valued and interpreted differently by each grower based on their own personal preference and local growing conditions. Displaying the data from such trials in a way that allows growers to quickly and intuitively compare multiple performance traits simultaneously and between many cultivars may facilitate the ability of growers to select cultivars that best suit their particular needs. Radar plots, therefore, may be a particularly valuable tool for communicating results from cultivar or variety trials to farmers and other stakeholders who must base their decisions on the evaluation of multiple performance criteria. As an example, growers prioritizing both leaf mold resistance and marketable yield might choose between 'Massada', which had more smaller fruit, as compared with 'Geronimo', 'Rebelski', 'Panzer', and 'Imperial 643', which produced fewer larger fruit, depending on their market preferences. Growers prioritizing large size and stable performance might select 'Brandywine', though they would be sacrificing marketable yields.

Radar plots are best suited to a suite of quantitative metrics; therefore, it should be noted that, for example, factors such as name recognition and "fruit quality" can be equally important as yield to a grower and difficult to incorporate into this graphic. Therefore, cultivars such as Brandywine, Jet Star, or others, may appear undervalued. Additionally, it should also be noted that given the nature of the design of this experiment, intercultivar interactions might have led to observations that may not directly scale up to entire tunnels grown into a single cultivar. For example, the expression of disease symptoms would likely change as a function of the susceptibility of the cultivar and the disease load of other cultivars in the same tunnel.

Our results suggest that several of the tomato cultivars examined in the study may be well suited for high tunnel production in the northeastern United States. Future trials should include a greater diversity of cultivars and occur under a greater range of high tunnel management environments so as to be more broadly representative of the diversity of growing environments encountered in high tunnel production systems in the northern New England region. Making the data from these trials available in alternative formats, such as radar plots, may help facilitate the selection of cultivars that are beneficial to farmers and consumers alike.

\section{Literature cited}

Blomgren, T. and T. Frisch. 2007. High tunnels: Using low-cost technology to increase yields, improve quality and extend the season. Univ. Vermont Ctr. Sustainable Agr., Burlington, VT.

Bogash, S. 2011. Report, high tunnel fresh market slicer tomato variety trial 2011. 15 Dec. 2014. <http://extension.psu.edu/ plants/vegetable-fruit/research-reports/ report-high-tunnel-fresh-market-slicertomato-variety-trial-201l>.

Carey, E.E., L. Jett, W.J. Lamont, T.T. Nennich, M.D. Orzolek, and K.A. Williams. 2009. Horticultural crop production in high tunnels in the United States: A snapshot. HortTechnology 19:37-43.

Cimen, I., V. Pirinc, I. Doran, and B. Turgay. 2010. Effect of soil solarization and arbuscular mycorrhizal fungus (Glomus intraradices) on yield and blossom-end rot of tomato. Intl. J. Agr. Biol. 12:551-555.

Curtis, M.D., J. Gore, and R.P. Oliver. 1994. The phylogeny of the tomato leaf mold fungus Cladosporim fulvum syn fulvia-fulva by analysis of rDNA sequences. Curr. Genet. 25:318-322.

Emmons, C.L.W. and J.W. Scott. 1997. Environmental and physiological effects on cuticle cracking in tomato. J. Amer. Soc. Hort. Sci. 122:797-801.

Howell, J.C. and R.V. Hazzard. 2012. 2012-2013 New England vegetable management guide. Univ. Massachusetts Ext. Veg. Program, Amherst, MA.

Hunter, B., D. Drost, B. Black, and R. Ward. 2012. Improving growth and productivity of early-season high-tunnel tomatoes with targeted temperature additions. HortScience 47:733-740.

Hutton, M.G. and D.T. Handley. 2006. Vegetable varieties for Maine gardens. Univ. Maine Coop. Ext. Publ. Bul. 2190.

Jones, H., J.M. Whipps, and S.J. Gurr. 2001. The tomato powdery mildew fungus Oidium neolycopersici. Mol. Plant Pathol. 2:303-309. 
Jones, J.B., T.A. Zitter, T.M. Momol, and S.A. Miller. 2014. Compendium of tomato diseases and pests. 2nd ed. APS Press, St. Paul, MN.

Joosten, M.H.A.J. and P.J.G.M. de Wit. 1999. The tomato-Cladosporium fulvum interaction: A versatile experimental system to study plant-pathogen interactions. Annu. Rev. Phytopathol. 37:335-367.

Lamont, W., M.D. Orzolek, E.J. Holcomb, K. Demchak, E. Burkhart, L. White, and B. Dye. 2003. Production system for horticultural crops grown in the Penn State high tunnel. HortTechnology 13:358-362.

Martinez-Blanco, J., P. Munoz, A. Anton, and J. Rieradevall. 2011. Assessment of tomato Mediterranean production in openfield and standard multi-tunnel greenhouse, with compost or mineral fertilizers, from an agricultural and environmental standpoint. J. Clean. Prod. 19:985-997.

McMaster, G.S. and W.W. Wilhelm. 1997. Growing degree-days: One equation, two interpretations. Agr. For. Meteorol. 87:291-300.

Monroe, J.S., M.H. Restrepo, J.K. Eck, S.R. Johnson, K.B. Norris, and S. Clinton. 2010. Midwest vegetable trial report for 2010: Tomato variety trial, 2010. 15 Dec. 2014. <https://ag.purdue.edu/hla/ fruitveg/Documents/pdf/reports/91_Monroe_Tomato_Variety\%20trial_LR.pdf $>$.
O'Connell, S., C. Rivard, M.M. Peet, C. Harlow, and F. Louws. 2012. High tunnel and field production of organic heirloom tomatoes: Yield, fruit quality, disease, and microclimate. HortScience 47:1283-1290.

Paradikovic, N., T. Teklic, T. Vinkovic, G. Kanizai, M. Lisjak, J. Mustapic-Karlic, and L. Bucan. 2010. The incidence of BER-affected tomato fruits under influence of the form of $\mathrm{N}$ fertilizer. J. Food Agr. Environ. 8:201-205.

Peet, M.M. and D.H. Willits. 1995. Role of excess water in tomato fruit cracking. HortScience 30:65-68.

Rogers, M.A. and A.L. Wszelaki. 2012. Influence of high tunnel production and planting date on yield, growth, and early blight development on organically grown heirloom and hybrid tomato. HortTechnology 22:452-462.

Saure, M.C. 2001. Blossom-end rot of tomato (Lycopersicon esculentum Mill.) - A calcium- or a stress-related disorder? Sci. Hort. 90:193-208.

Seifi, A., D. Gao, Z. Zheng, S. Pavan, L. Faino, R.G.F. Visser, A.A. Wolters, and Y. Bai. 2014. Genetics and molecular mechanisms of resistance to powdery mildews in tomato (Solanum lycopersicum) and its wild relatives. Eur. J. Plant Pathol. 138:641-665.
Smith, R.G., T.P. Gareau, D.A. Mortensen, W.S. Curran, and M.E. Barbercheck. 2011. Assessing and visualizing agricultural management practices: A multivariable hands- on approach for education and extension. Weed Technol. 25:680-687.

Taylor, M.D. and S.J. Locascio. 2004. Blossom-end rot: A calcium deficiency. J. Plant Nutr. 27:123-139.

Uzun, S. 2007. The effect of temperature and mean cumulative daily light intensity on fruiting behavior of greenhouse-grown tomato. J. Amer. Soc. Hort. Sci. 132:459466.

Waterer, D. 2003. Yields and economics of high tunnels for production of warmseason vegetable crops. HortTechnology 13:339-343.

Wells, O.S. and J.B. Loy. 1993. Rowcovers and high tunnels enhance crop production in the northeastern United States. HortTechnology 3:92-95.

Whipps, J.M., S.P. Budge, and J.S. Fenlon. 1998. Characteristics and host range of tomato powdery mildew. Plant Pathol. $47: 36-48$.

Williams, T.V. and W. Roberts. 2002. Is vegetable variety evaluation and reporting becoming a lost art? An industry perspective. HortTechnology 12:553-559. 